\section{You're the best man for this job, son. What a coincidence!}

SIR - As an Italian PhD student abroad, I agree with your Editorial 'Situations vacant' (Nature 456, 142; 2008), in which you discuss issues influencing the hiring of academic staff in Italy. The day after this was published, details of yet another scandal in the Italian academic world appeared in the Italian newspaper Corriere della Sera under the headline 'A single candidate for a research position: the professor's son' (http:// tinyurl.com/5nsd2c).

The emergence of a single candidate in the concorso (national competition) for a position at the University of Messina in Sicily is surprising in itself: such concorsi are rarely held, owing to the limited funding available to Italian universities. Even more disturbing is the fact that two other candidates stood down unexpectedly at the last minute, ensuring the victory of the one who remained.

The successful candidate's father had retired from the same faculty, so his alleged reply in an interview by the newspaper's reporter to a question regarding the candidate's identity was perplexing: "Ask the university. How can I know him? This is a national competition!" He apparently added, "If my son is the only candidate, it is because there were no other people that fulfil the requirements", and continued with the disturbing reflection that professors' sons are more suitable for such positions because their home environment has given them the right mentality.

This kind of event is all too familiar in Italy. An example of an 'academic dynasty' was reported last year in the newspaper La Repubblica (http://tinyurl. com/5lqwul). But the words of a professor who reportedly doesn't recognize the anomaly of the system, while claiming superiority for his offspring, add another distasteful component.

Considering this situation,
I would like to conclude by changing your Editorial's statement into a question. Should Italy's universities be free to hire whom they want?

Albert Ruggi Laboratory of Supramolecular Chemistry and Technology, University of Twente, PO Box 217, 7500 AE Enschede, The Netherlands e-mail: a.ruggi@tnw.utwente.nl

Readers are welcome to comment at http://tinyurl.com/5lg42f.

\section{Online archives are revealing uncensored history of science}

\section{SIR - Search engines are} invaluable for finding out about the latest research but, thanks to publishers' efforts to digitize back issues of scientific journals, we can now also search deep into the past. And what turns up isn't necessarily pretty.

In the CAB (Centre for

Agricultural Bioscience) abstracts database, for example, I found more than 100 articles written by the discredited Soviet geneticist Trofim Denisovich Lysenko. One of his most astounding reports, in a 1947 issue of the journal Literaturnaya Gazeta, declaimed that: "intraspecific competition does not occur... the opposition of bourgeois geneticists to this theory is attributed to their desire to justify capitalist exploitation, which is essentially a struggle within the human species".

Another search, using Web of Knowledge, brought up hundreds of Chinese scientific articles from the decades after Mao Zedong came to power in 1949, with titles such as 'Chairman Mao's brilliant philosophic thought guides me in winning triple cropping with high yield' (Li K. C. Sci. China Ser. A 20, 391-391; 1977).

Also using Web of Knowledge, I came upon 70 research papers by Claus Schilling, the Nazi war criminal who conducted medical experiments on prisoners in Dachau concentration camp. None of his wartime research is in the database but, as I scrolled through the record of his publications, I found myself looking for the point at which he had gone wrong.

These examples stand in contrast with the high-minded official version of science history that we read in textbooks. As Thomas Kuhn remarked in The Structure of Scientific Revolutions (Univ. Chicago Press, 1962), science is like Big Brother's society in George Orwell's 1984 - constantly rewriting history to show itself in the best light.

But will this censorship be possible when every politically motivated, unethical and demonstrably incorrect scientific article breaks out from dusty library storerooms to appear online? How will anyone be able to believe that science is an honest quest for truth, when its inglorious past is a mouse click away?

William Burns Diamantina Institute for Cancer, Immunology and Metabolic Medicine, University of Queensland, Princess Alexandra Hospital, Ipswich Road, Woolloongabba, Queensland 4102, Australia e-mail:w.burns@uq.edu.au

\section{Finding of unusual soil on Mars could stem from tools used}

SIR - In your News story 'Phoenix fades away' (Nature 456, 8-9; 2008), you suggest that the polar soil analysed by NASA's Phoenix Lander "was like nothing else tested so far on Mars". But the soils sampled may not be unusual at all. An alternative explanation may lie with the instruments used for the analysis, given that these had never been used before.

The Martian soils were found to be alkaline and to contain trace amounts of perchlorates and carbonates. But they may still be similar to the soils analysed by previous landers. The Phoenix measurement of soil $\mathrm{pH}$ ( $\mathrm{pH}$ 8.3) was carried out by dissolving small amounts of soil in liquid water. Geochemical modelling indicates that adding water to the ionic composition of the most acidic environment described so far on Mars, Meridiani Planum, should give a $\mathrm{pH}$ of 9.2, according to my own calculations. The identification by the Mars Exploration Rover (MER) Opportunity of a set of minerals that could not precipitate in an alkaline solution, including sulphate evaporites, provides information about a post-settlement acidification at Meridiani. This was driven by gaseous carbon dioxide, sulphur dioxide and iron ions, neutralizing the $\mathrm{pH}$-raising capacity of the basaltic minerals in the host rock and allowing the synthesis of acidic minerals.

Also, the discovery of perchlorate as a result of diluting Martian dust in water and searching for the soluble salts it contains is not necessarily a unique characteristic of the Phoenix soils. The inferred presence of chlorides at all Martian landing sites may not be the sole explanation after the identification of chlorine. It has been known since the Viking missions in the seventies that conditions at the Martian surface are strongly oxidizing. This could be due, for example, to chlorine salts such as chlorites, chlorates and perchlorates that originated photochemically in the atmosphere.

Moreover, the signal for calcium carbonate encountered by Phoenix is in fact the same footprint found by Mars Global Surveyor in soils all around the planet in 2003, and by the MER Spirit in Gusev crater in 2004. The only difference is that these previous identifications uncovered magnesium carbonate.

It is, therefore, possible that if the previous landers had incorporated the same analysis capabilities as Phoenix, the results might have been very similar.

Alberto G. Fairén Space Science and Astrobiology Division, NASA Ames Research Center, MS 245-3, Moffett Field, California 94035, USA e-mail: afairen@arc.nasa.gov 